\title{
PERANCANGAN SISTEM INFORMASI PENJADWALAN PRAKTIKUM BERBASIS WEB PADA FAKULTAS TEKNOLOGI INFORMASI
}

\author{
Muharir $^{1)}$, Nur Alamsyah ${ }^{2)}$ \\ ${ }^{l}$ Fakultas Teknologi Informasi, Universitas Islam Kalimantan Muhammad Arsyad Al Banjari Banjarmasin \\ Email: muharir17@gmail.com \\ ${ }^{2}$ Fakultas Teknologi Informasi, Universitas Islam Kalimantan Muhammad Arsyad Al Banjari Banjarmasin \\ Email: uniskalam@gmail.com
}

\begin{abstract}
ABSTRAK
Penjawdalan yang dilakukan oleh Laboratorium Komputer Fakultas Teknologi Informasi masih dilakukan secara manual yaitu dengan memberikan selembar kertas dan mengumumkan ke setiap kelas proses pendaftaran dan pelaksanaan praktikum, cara kedua dengan menggunakan google form, cara ini lebih baik tetapi masih terdapat kekurangan yaitu banyaknya data namanama mahasiswa yang sama dan materi yang diambil pun sama sehingga asisten mengalami kesulitan dalam mengelola data dan mempengaruhi dalam penjadwlan.

Pada penelitian ini dirancang sebuah sistem informasi penjadwalan berbasis web dengan menggunakan permodelan sistem use case diagram, sistem pendaftaran dan juga informasi jadwal pelaksanaan praktikum secara online sehingga mahasiswa tidak lagi ketinggalan informasi daftar dan jadwal praktikum.

Sistem informasi penjadwalan praktikum di Laboratorium Komputer FTI dapat digunakan untuk input jadwal praktikum secara online sehingga lebih mudah dan cepat karena sistem dapat melakukan verifikasi terhadap praktikan yang akan melakukan input jadwal dengan mencocokkan pada database. Penggunaan sistem informasi penjadwalan praktikum ini juga mendukung kegiatan praktikum secara menyeluruh. Hal ini karena informasi mengenai praktikum yang terkait dengan asisten, praktikan, dan kepala lab dapat dilakukan dengan mudah, cepat, dan dapat diakses secara realtime.
\end{abstract}

Kata kunci : Sistem Informasi, penjadwalan, praktikum.

\section{PENDAHULUAN}

Fakultas Teknologi Informasi (FTI) sebagai salah satu fakultas yang didirikan untuk memenuhi kebutuhan akan teknologi, menghasilkan sumber daya manusia yang dapat memenuhi standart kebutuhan pasar kerja regional maupun nasional.

Fakultas ini memiliki dua program studi yaitu program studi Teknik Informatika dan Sistem Informasi. Fakultas Teknologi Informasi (FTI) memiliki mahasiswa yang lumayan banyak, dengan jumlah dosen sekitar 70 orang. Saat ini saja jumlah mahasiswa Teknik informatika sampai periode semester 2018/2019 sebanyak 4.419 mahasiswa, sedangkan program studi Sistem Informasi memiliki mahasiswa sebanyak 470 orang atau dapat dilihat pada tabel dibawah ini:
Tabel 1 Prodi

\begin{tabular}{|c|l|c|c|c|c|}
\hline No & \multicolumn{1}{|c|}{ Prodi } & $\begin{array}{c}\text { Mhs } \\
\text { Aktif }\end{array}$ & $\begin{array}{c}\text { Pinda- } \\
\text { han }\end{array}$ & Cuti & $\begin{array}{c}\text { Non } \\
\text { Aktif }\end{array}$ \\
\hline $\mathbf{1}$ & $\begin{array}{l}\text { Teknik } \\
\text { Informatika }\end{array}$ & 4.419 & 363 & 7 & 0 \\
\hline $\mathbf{2}$ & $\begin{array}{l}\text { Sistem } \\
\text { Informasi }\end{array}$ & 470 & 96 & 0 & 0 \\
\hline & Jumlah & 4.889 & 459 & 7 & 0 \\
\hline
\end{tabular}

Sumber : sia online uniska

Bagi Fakultas Teknologi Informasi (FTI) kegiatan praktek diluar jam belajar mengajar di kelas merupakan hal yang sangat penting bagi seluruh mahasiswa. Kegiatan praktek tersebut dapat menunjang pemahaman mahasiswa terhadap materi yang diberikan oleh dosen di dalam kelas.

Praktikum adalah subsistem dari perkuliahan yang merupakan kegiatan terstruktur dan terjadwal yang memberi 
kesempatan kepada mahasiswa untuk mendapatkan pengalaman yang nyata dalam rangka meningkatkan pemahaman mahasiswa tentang teori agar mahasiswa menguasai keterampilan tertentu yang berkaitan dengan suatu pengetahuan atau suatu mata kuliah.

Praktikum merupakan salah satu kegiatan pendukung dalam proses pembelajaran, disamping pemberian teoriteori, praktikum juga merupakan kegiatan rutin dan bersifat wajib yang harus diikuti mahasiswa. Seluruh kegiatan praktikum dikelola oleh asisten, seluruh kegiatan laboratorium tetap harus mendapatkan persetujuan dari pembina laboratorium. Salah satu hak dan kewajiban asisten dalam kegiatan praktikum adalah mengatur seluruh kegiatan praktikum dari pengaturan jadwal praktikum sampai proses pemberian nilai praktikum kepada mahasiswa yang menjadi peserta praktikum atau sering disebut sebagai praktikan.

Penentuan jadwal praktikum merupakan hal yang sangat penting dalam pelaksanaan kegiatan praktikum karena jadwal praktikum yang diberikan harus disesuaikan dengan jadwal kuliah yang sedang dilaksanakan oleh praktikan. Karena begitu padatnya jadwal perkuliahan sehingga pengaturan jadwal praktikum ini menyesuaikan kelas yang terdiri kelas reguler pagi dan malam Banjarmasin dan Banjarbaru dan kelas non regular, dengan kondisi seperti ini, pada pelaksanaannya masih sering terjadi adanya kesamaan antara jadwal praktikum dengan jadwal kuliah yang sedang dilaksanakan oleh praktikan atau dengan kata lain jadwal praktikum bentrok dengan jadwal kuliah.

Selain itu masalah lain yang terjadi adalah cara penyampaian pelaksanaan praktikum, mulai dari mendaftar sampai informasi jadwal praktikum, kadang mahasiswa tidak mengetahui kapan pelaksanaan praktikum, kemudian ditambah cara mendaftarnya menggunakan media kertas dengan menuliskan nama-nama peserta praktikum dan mahasiswa harus ke fakultas untuk mendaftar, kesulitan lainnya asisten mengelola data-data tersebut harus menyalin dan menyusun ulang ke komputer data-data yang ada.

\section{METODE PENELITIAN}

Metode pengembangan sistem perangkat lunak mengacu pada model waterfall. Model waterfall adalah salah satu model pengembangan software, dimana kemajuan suatu proses dipandang sebagai terus mengalir ke bawah seperti air terjun. Dalam Model Waterfall, setiap tahap harus berurutan, dan tidak dapat meloncat ketahap berikutnya, harus menyelesaikan tahap pertama baru lanjut ke tahap ke dua dan seterusnya.

Langkah-langkah model waterfall dapat dilihat pada gambar dibawah Ini:

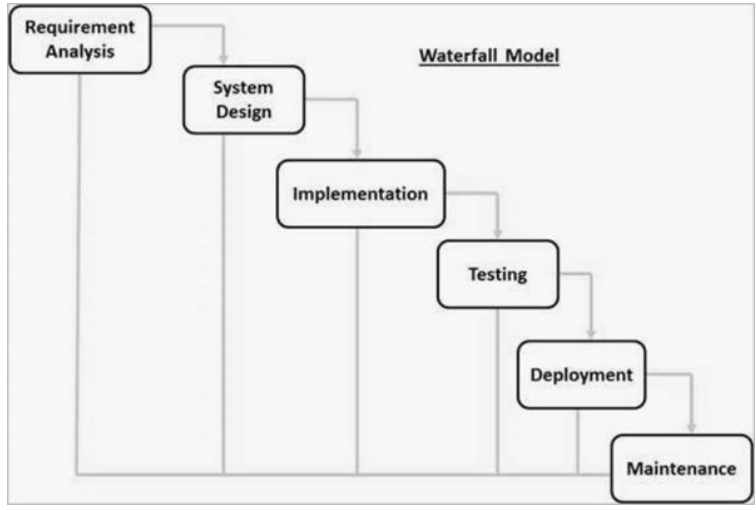

Gambar 1 Langkah-langkah model waterfall

1. Requirement Gathering and analysis Tahap requirement atau spesifikasi kebutuhan sistem adalah mengumpul-kan kebutuhan secara lengkap kemudian kemudian dianalisis dan didefinisikan kebutuhan yang harus dipenuhi oleh program yang akan dibangun. Fase ini harus dikerjakan secara lengkap untuk bisa menghasilkan desain yang lengkap.

2. Sistem Design

Tahap selanjutnya adalah design, desain dikerjakan setelah kebutuhan selesai dikumpulkan secara lengkap.

3. Implementation

Selanjutnya tahap implementasi, yaitu desain program diterjemahkan ke dalam kode-kode dengan menggunakan bahasa pemrograman yang sudah ditentukan. Program yang dibangun langsung diuji baik secara unit.

4. Integration and Testing 
Penyatuan unit-unit program kemudian diuji secara keseluruhan (sistem testing)

5. Deployment of Sistem

Mengoperasikan program dilingkungannya dan melakukan pemeliharaan, seperti penyesuaian atau perubahan karena adaptasi dengan situasi sebenarnya.

6. Maintenance

Proses pemeliharaan sistem yang sudah dibangun.

Berdasarkan rancangan penelitian, tahap pengambilan data dilakukan dengan cara mengamati kegiatan yang sedang berlangsung dan meminta copy file excel yang sering digunakan untuk menjadwalkan praktikum. Selain itu juga dilakukan dialog dengan asisten praktikum untuk mengetahui kelas apa saja yang akan dibuat, zona praktikum yang akan dilakukan dan rancang bangun system yang akan di design dan di impelentasikan ke dalam bentuk mockup/wireframe.

Dari tahap pengambilan data, disimpulkan bahwa praktikum yang dilaksanakan meliputi :

Tabel 2 Mata Kuliah Praktik

\begin{tabular}{|r|l|c|}
\hline No & \multicolumn{1}{|c|}{$\begin{array}{c}\text { Mata Kuliah } \\
\text { Praktik }\end{array}$} & $\begin{array}{c}\text { Semes } \\
\text { ter }\end{array}$ \\
\hline $\mathbf{1}$ & $\begin{array}{l}\text { Algoritma dan Pemrograman 1 } \\
\text { (Pascal Dasar) }\end{array}$ & 1 \\
\hline $\mathbf{2}$ & Sistem Basis Data 1 & 1 \\
\hline $\mathbf{3}$ & Program Paket Niaga & 1 \\
\hline $\mathbf{4}$ & Pemrograman Visual 1 & 2 \\
\hline $\mathbf{5}$ & Design Grafis & 2 \\
\hline $\mathbf{6}$ & Jaringan Komputer & 3 \\
\hline $\mathbf{7}$ & Pemrograman Web 1 & 3 \\
\hline $\mathbf{8}$ & $\begin{array}{l}\text { Pemrograman Visual 2 (Visual } \\
\text { Basic Dasar) }\end{array}$ & 4 \\
\hline $\mathbf{9}$ & $\begin{array}{l}\text { Pemrograman Berbasis Objek 1 } \\
\text { (Java Dasar) }\end{array}$ & 4 \\
\hline $\mathbf{1 0}$ & Pemrograman Web 2 & 4 \\
\hline $\mathbf{1 1}$ & Teknologi Multimedia & 5 \\
\hline $\mathbf{1 2}$ & $\begin{array}{l}\text { Pemrograman Visual 3 (Visual } \\
\text { Basic Lanjut) }\end{array}$ & 5 \\
\hline $\mathbf{1 3}$ & Android & 6 \\
\hline $\mathbf{1 4}$ & Mikro Kontroller & 6 \\
\hline & & \\
\hline
\end{tabular}

\section{HASIL DAN PEMBAHASAN}

\subsection{Rancangan Model Sistem}

Perancangan model sistem adalah merancang atau mendesain sistem yang baik, isinya adalah langkah-langkah operasi dalam pengolahan data dan prosedur untuk operasi sistem. Kegiatan yang dilakukan pada tahap ini yaitu merancang atau mendesain sistem yang baik, mendesain pemodelan sistem yang baik, mengenali dan mendefinisikan masalah pembuatan sistem ini sehingga jika ada kesalahan ada alternatif pemecahannya.

\subsection{Use Case Diagram}

Use case mendeskripsikan sebuah interaksi antara satu atau lebih aktor dengan sistem informasi yang akan dibuat. Use case diagram menggambarkan fungsionalitas dari sebuah system yang ditekankan adalah "apa" yang diperbuat sistem, dan bukan "bagaimana".

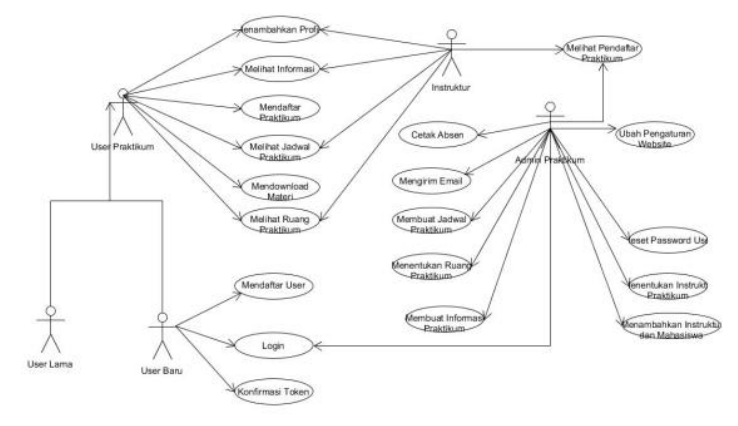

Gambar 2 Use Case Diagram

\subsection{Rancangan Tabel}

Berikut rancangan tabel data-data dalam perancangan sistem informasi penjadwalan praktikum berbasis web pada fakultas teknologi informasi, yaitu:

1. Tabel User

2. Tabel Mahasiswa

3. Tabel Praktikum

4. Tabel Instruktur

5. Tabel mahasiswa_praktikumdetail

6. Tabel praktikumdetail

7. Tabel Ruangan

8. Tabel praktikumdetail_ruang

9. Tabel praktikumdetail_praktikum

10. Tabel deskripsi

11. Tabel praktikumdetail_instruktur

\subsection{Rancangan Tampilan}




\section{Design Wireframe}

Rancangan antarmuka masukan sistem berfungsi untuk menjelaskan tentang perancangan aplikasi yang akan dibangun. Hal ini dilakukan untuk mempermudah pengguna dalam mengetahui proses yang terdapat pada aplikasi yang akan dibangun. Untuk lebih jelasnya rancangan antarmuka masukan sistem dapat dilihat dibawah ini.

\section{Rancangan Login}

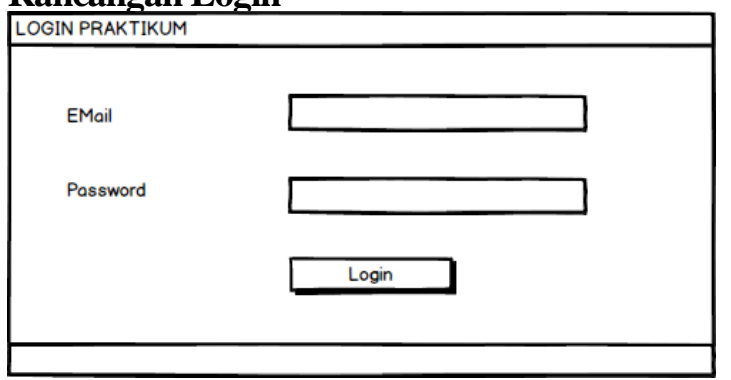

Gambar 3 Rancangan Login

\section{Halaman Menu Utama}

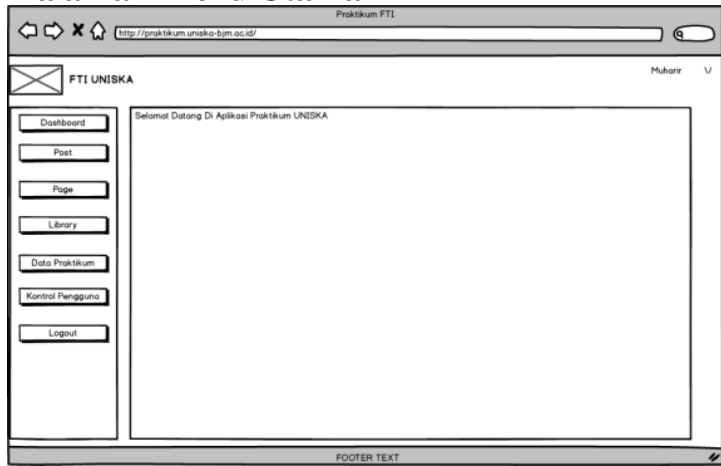

Gambar 4 Menu Utama

\section{Enrollment Mahasiswa Sesuai Kelas}

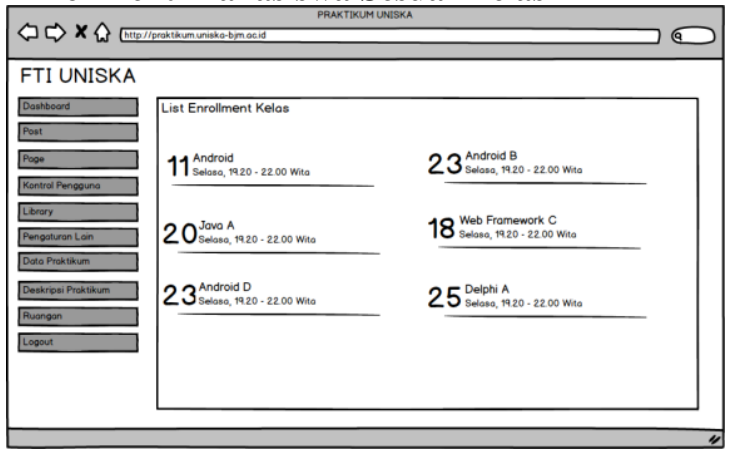

Gambar 5 Enrollment Mahasiswa Sesuai Kelas

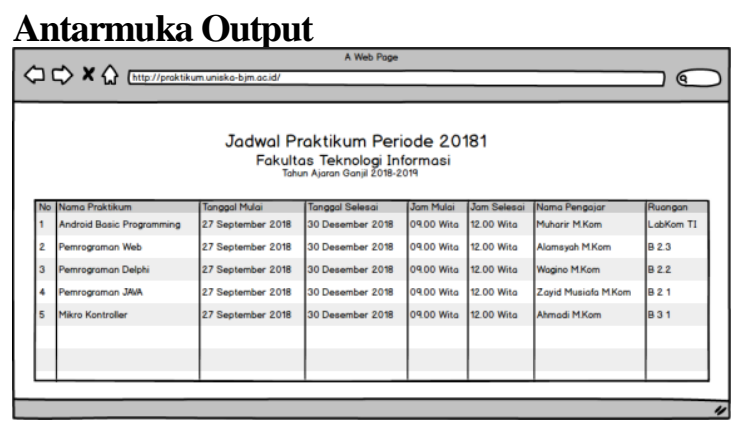

Gambar 6 Output

\section{Implementasi}

Implementasi adalah tahapan dimana gambaran awal program dibuat dan ditulis dalam bahasa yang dimengerti komputer sehingga menghasilkan program yang di inginkan. Pada tahap ini semua tahapan sebelumnya baik dari perancangan table dan mockup yang ada mulai di implementasikan dengan penulisan kode-kode program.

\section{Tampilan Halaman Awal}

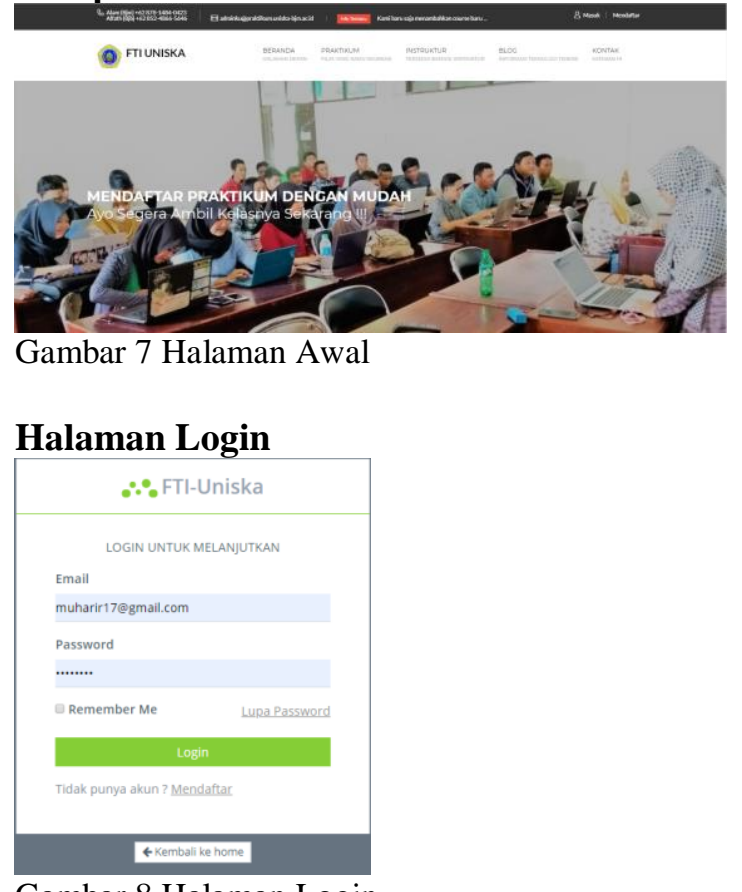

Gambar 8 Halaman Login 


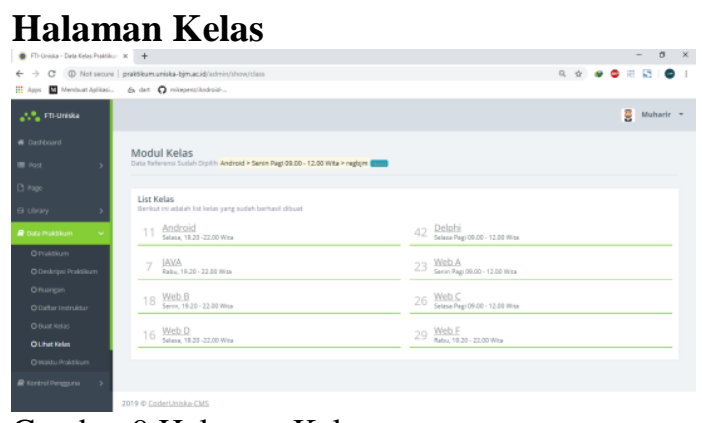

Gambar 9 Halaman Kelas

\section{Jadwal Praktikum}
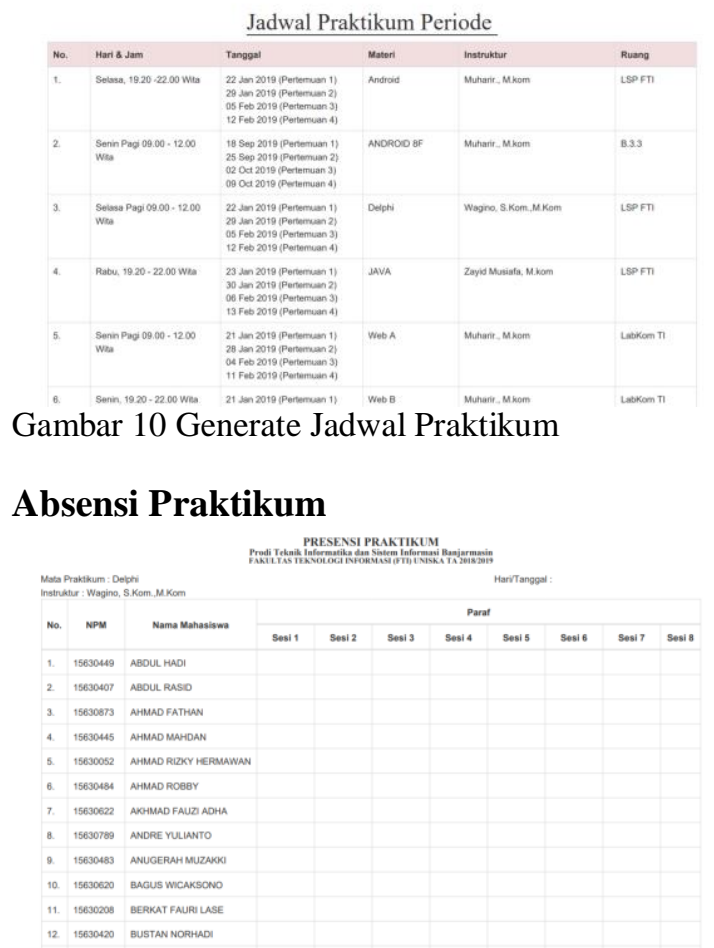

Gambar 11 Generate Absensi Praktikum

\section{KESIMPULAN DAN SARAN}

Berdasarkan hasil implementasi dan testing yang dilakukan pada sistem informasi penjadwalan praktikum berbasis web, dapat ditarik kesimpulan sebagai berikut :

1. Sistem informasi penjadwalan praktikum berbasis web dapat mengatasi kesulitan penjadwalan dan panjangnya antrian pelaksanaan praktikum yang dikarenakan menyesuaikan jadwal perkuliahan.

2. Pengumuman pelaksanaan praktikum tidak lagi diumumkan kesetiap kelas melainkan mahasiswa dapat mengecek langsung ke website praktikum dan memilih praktikum yang diminatinya sesuai dengan waktu yang di inginkan.

3. Kesulitan asisten dalam mengelola datadata praktikum dapat diatasi dari yang awalnya pencatatan manual beralih ke sistem yang lebih rapih dan terstruktur, baik dari segi laporan, absensi, bahkan riwayat praktikum persemester tiap mahasiswa dapat dilihat pada sistem informasi penjadwalan praktikum. Sehingga asisten dapat mengevaluasi setiap kegiatan praktikum yang dilaksanakan.

4. Mahasiswa dapat mendownload modul praktikum dan tersedia tutorial-tutorial yang di tulis oleh para instruktur untuk memudahkan mahasiswa mempelajari tiap materi, teknik, dan perkembangan teknologi terbaru.

Meskipun sistem informasi penjadwalan praktikum sudah memberikan hasil yang lebih baik, namun ada beberapa hal yang dapat dikembangkan untuk penelitian selanjutnya :

1. Integrasi dengan database Sistem Informasi Akademik SIA UNISKA, agar monitoring pendaftar sistem informasi akademik lebih mudah.

2. Dikembangkan ke bentuk mobile apps sehingga dapat ditambahkan push notification di dalamnya. Untuk pemberitahuan informasi real time.

\section{REFERENSI}

Pressman, Roger S. (2002). Rekayasa Perangkat Lunak (Pendekatan Praktisi Buku Satu).Edisi keempat.Yogyakarta: Andi

Barata. 2014. Sistem Informasi Akademik Laboratorium Kimia Dasar. Skripsi. Program Studi Ilmu Komputer FMIPA UGM. Yogyakarta.

Basuki, A., P. 2010. Membangun Framework Berbasis PHP dengan Framework CodeIgniter. Penerbit Lokomedia. Yogyakarta.

Benedetti, R. Dan Cranley, R. 2011. Head First jQuery, O'Reilly Media, Inc. 
Cochran, D. 2012. Twitter Bootstrap Web Development How-To. PACKT Publiseher.

Date, C. 2002. An Introduction to Database System, Sevinth Edition. New York: Addison- Wesley Publishing Company.

Demiawansyah, A. 2014. Sistem Informasi Persiapan Praktikum di Program Studi Komputer dan Sistem Informasi SV UGM. Tugas Akhir. Program Studi Komputer dan Sistem Informasi SV UGM. Yogyakarta.

Dennis, A., Wixom, B., \& Roth, R. 2009. System Analysis and Design. John Wiley and Sons Inc.

Jogiyanto. 2005. Analisis dan Desain Sistem Informasi: Pendekatan Terstruktur Teori dan Praktik Aplikasi Bisnis. Yogyakarta: Penerbit Andi.

Kossiakof. 2002. System Engineering Principles and Practice. John Wiley and Sons Inc.

Laksono. 2013. Aplikasi Penjadwalan Perkuliahan Praktikum Berbasis Web di Pusat Laboratorium Terpadu UIN Syarif. Skripsi. UIN Syarif. Jakarta.

Mansfield, R. 2005. CSS Web Design For Dummies. John Wiley and Sons, Inc.

Mc Farland, D. 2013. CSS3: The Missing Manual. O'Reilly Media, Inc.

Mc Farland, D. 2009. Javascript and Query: The Missing Manual, Second Edition. O'Reilly Media, Inc.

Nixon, R. 2009. Learning PHP, MySQL and Javascript. O'Reilly Media, Inc.

Powell, T. 2010. HTML and CSS: The Complete Reference, Fifth Edition. The McGraw- Hill Companies, Inc.

Powers, D. 2012. Beginning CSS3: Mastering The Language of Web Design. Apress. 